\title{
Tazobactam and piperacillin-induced thrombocytopenia: A case report
}

\author{
HONG CHEN ${ }^{1,2^{*}}$, ZHEN FAN $^{1,2^{*}}$, FEI GUO $^{3 *}$, YUMIN YANG $^{1,2}$, JIE LI $^{1,2}$, JIE ZHANG $^{1,2}$, \\ YUDAN WANG ${ }^{1,2}$, JIANWEI LE ${ }^{1,2}$, ZHIYU WANG ${ }^{1,2}$ and JIANHUA ZHU ${ }^{1,2}$ \\ ${ }^{1}$ Intensive Care Unit, Ningbo First Hospital; ${ }^{2}$ Intensive Care Unit, Ningbo Hospital of Zhejiang University; \\ ${ }^{3}$ Clinical Laboratory, Ningbo First Hospital, Ningbo, Zhejiang 315000, P.R. China
}

Received March 9, 2015; Accepted October 29, 2015

DOI: $10.3892 / \mathrm{etm} .2016 .3062$

\begin{abstract}
The present study reports a case of tazobactam and piperacillin (TZP)-induced thrombocytopenia in an elderly patient, from which complete clinical data and peripheral blood samples were collected. Platelet numbers were decreased 1 day following TZP treatment initiation; however, they were revealed to have increased 1-2 days following withdrawal of TZP, and had reached normal levels 3-5 days later. There was no evidence of bone marrow suppression, antibodies against peripheral plasma platelets were absent and levels of complement C3 were decreased. These results suggested that TZP was able to cause rapid and reversible thrombocytopenia, which was not associated with bone marrow suppression but may have involved activation of complement $\mathrm{C} 3$. The results of the present study therefore suggest that doctors should be aware of the risk of thrombocytopenia in patients treated with TZP.
\end{abstract}

\section{Introduction}

In normal human blood, every $\mathrm{mm}^{3}$ contains $10-30 \times 10^{4}$ platelets, the average lifespan of which is $8-10$ days (1). If the platelet count decreases to $<10 \times 10^{4} \mathrm{~mm}^{3}$, the patient is diagnosed with thrombocytopenia (2). Thrombocytopenia, if severe, may cause symptoms, such as mucosal bleeding from the nose, mouth and gastrointestinal tract (3). Tazobactam and piperacillin (TZP) are antibiotics that are used to treat the majority of infections caused by $\beta$-lactamase-producing

Correspondence to: Dr Jianhua Zhu or Dr Hong Chen, Intensive Care Unit, Ningbo First Hospital, 59 Liuting Street, Ningbo, Zhejiang 315000, P.R. China

E-mail: zhujianhua201107@126.com

E-mail: cherry840329@163.com

*Contributed equally

Abbreviations: ESR, erythrocyte sedimentation rate; TZP, tazobactam and piperacillin

Key words: piperacillin-tazobactam, thrombocytopenia bacteria $(4,5)$. Common adverse reactions associated with TZP treatment include neutropenia, leukopenia and thrombocytopenia, urticaria, allergic shock, exfoliative dermatitis, and adverse reactions of the nervous system (6-8). These adverse reactions typically occur simultaneously and thrombocytopenia rarely manifests independently of other symptoms (9). The patients with thrombocytopenia associated with TZP may report severe bleeding at a number of locations, including gastrointestinal tract bleeding, a cerebral hemorrhage or subcutaneous bleeding (10) The mechanism by which TZP causes thrombocytopenia is unclear, however, drug-induced thrombocytopenia is typically hypothesized to have three possible underlying mechanisms; these are immune-mediated, direct platelet number decreases and bone marrow suppression (11). The present study investigated the occurrence of thrombocytopenia in a single patient treated with TZP, as well as its clinical features, in order to investigate potential underlying mechanisms.

\section{Case report}

A 76-year-old male patient with a 20-year history of hypertension was admitted to the intensive care unit (ICU) of Ningbo First Hospital (Ningbo, China) in February 2013 complaining of dizziness, vomiting and slurred speech. Informed consent was obtained from the patient, after which blood samples were taken and a clinical evaluation was conducted. A computed tomography scan of the brain and lungs suggested that the patient was suffering from a cerebral infarction and pneumonia. The patient was treated with aspirin, in order to reduce the levels of platelets, with nifedipine, in order to control blood pressure and improve cerebral circulation, and with TZP (dose, $4.5 \mathrm{~g}$; administered every $8 \mathrm{~h}$ intravenously), starting from the 3rd day following admission. However, the platelet levels of the patient rapidly dropped to $13 \times 10^{9}$ platelets $/$, but the size of the liver and spleen were deemed normal, determined using B-scan ultrasound examination. In order to ameliorate the platelet deficit, aspirin treatment was terminated, and the patient was administered 10 units infused platelets, $40 \mathrm{mg}$ methylprednisolone and $5 \mathrm{~g}$ gamma globulin once daily, for 2 weeks. However, the platelet levels remained low and, on the 16th day following admission, TZP treatment was substituted with meropenem 
Table I. WBC and PLT levels altered over time during TZP and meropenem treatment.

\begin{tabular}{|c|c|c|}
\hline Day & WBC $\left(10^{9} / 1\right)$ & $\operatorname{PLT}\left(10^{9} / 1\right)$ \\
\hline 1 & 7.6 & 223 \\
\hline 3 & 16.8 & 13 \\
\hline 4 & 8.4 & 22 \\
\hline 5 & 6.1 & 45 \\
\hline 6 & 8.7 & 36 \\
\hline 7 & 3.1 & 20 \\
\hline 8 & 13.4 & 56 \\
\hline 9 & 13.1 & 69 \\
\hline 10 & 13.5 & 72 \\
\hline 11 & 10 & 49 \\
\hline 12 & 10.9 & 38 \\
\hline 13 & 12.9 & 12 \\
\hline 14 & 8 & 20 \\
\hline 15 & 9 & 18 \\
\hline 16 & 9.3 & 19 \\
\hline 17 & 7.9 & 42 \\
\hline 18 & 10.3 & 197 \\
\hline 19 & 7.7 & 145 \\
\hline 20 & 8.4 & 16.2 \\
\hline 21 & 11.9 & 75 \\
\hline 22 & 8.4 & 35 \\
\hline 23 & 7 & 19.6 \\
\hline 24 & 4.6 & 32.6 \\
\hline 25 & 9.7 & 105 \\
\hline 26 & 4.1 & 57 \\
\hline 27 & 5.1 & 61 \\
\hline 28 & 7 & 92 \\
\hline 29 & 7.4 & 107 \\
\hline
\end{tabular}

TZP treatment was initiated on days 3 and 20, and was withdrawn and replaced by meropenem treatment on days 16 and 23 . WBC, white blood cells; PLT, platelets; TZP, tazobactam and piperacillin.

treatment (dose, $1.0 \mathrm{~g}$; administered every $8 \mathrm{~h}$ intravenously) in order to restore platelets to normal levels (Table I and Fig. 1A). Over the next 2 days, the platelet count of the patient increased from $19 \times 10^{9}$ to $19.7 \times 10^{10}$ platelets/1. On the 20th day following admission, the TZP treatment regimen was restored, inducing the platelet count of the patient to decrease to $16.2 \times 10^{9}$ platelets/1; substitution of TZP with meropenem on the 23 rd day following admission again caused the platelet count to return to normal $\left(10.5 \times 10^{10}\right.$ platelets/l) over a period of 2 days. The preliminary diagnosis of the patient was idiopathic thrombocytopenic purpura.

A laboratory examination demonstrated that the erythrocyte sedimentation rate $(\mathrm{ESR} ; 37 \mathrm{~mm} / \mathrm{h})$ and the levels of immunoglobulin ( $\mathrm{Ig}) \mathrm{G}(2,260 \mathrm{mg} / \mathrm{dl})$ were increased; however, IgA, Ig M, complement C3, complement C4, streptolysin and rheumatoid factors, anti-cardiolipin (ACA), antinuclear, anti-Smith, anti-U1-nuclear ribonucleoprotein, anti-Ro/Sjögren's-syndrome-related antigen A, anti-Ro-52,
Table II. Laboratory examination of the patient.

\begin{tabular}{|c|c|c|c|c|}
\hline Variable & Result & Change & Normal range & Unit \\
\hline ESR & 37 & + & $<15$ & $\mathrm{~mm} / \mathrm{h}$ \\
\hline $\mathrm{IgG}$ & 2,260 & + & $726-1,685$ & $\mathrm{mg} / \mathrm{dl}$ \\
\hline $\operatorname{Ig} \mathrm{A}$ & 158 & $\mathrm{n}$ & 69-382 & $\mathrm{mg} / \mathrm{dl}$ \\
\hline $\operatorname{IgM}$ & 67 & $\mathrm{n}$ & $63-277$ & $\mathrm{mg} / \mathrm{dl}$ \\
\hline $\mathrm{C} 3$ & 70.4 & - & $85-193$ & $\mathrm{mg} / \mathrm{dl}$ \\
\hline $\mathrm{C} 4$ & 12.1 & $\mathrm{n}$ & $12-36$ & $\mathrm{mg} / \mathrm{dl}$ \\
\hline ASO & 70.9 & $\mathrm{n}$ & $0-200$ & $\mathrm{IU} / \mathrm{ml}$ \\
\hline $\mathrm{RF}$ & $<20$ & $\mathrm{n}$ & $0-30$ & $\mathrm{IU} / \mathrm{ml}$ \\
\hline ACA & $\mathrm{N}$ & $\mathrm{n}$ & $\mathrm{N}$ & $\mathrm{N} / \mathrm{A}$ \\
\hline ANCA & $\mathrm{N}$ & $\mathrm{n}$ & $\mathrm{N}$ & N/A \\
\hline ANA & $\mathrm{N}$ & $\mathrm{n}$ & $\mathrm{N}$ & N/A \\
\hline $\mathrm{Sm}-\mathrm{Ab}$ & $\mathrm{N}$ & $\mathrm{n}$ & $\mathrm{N}$ & $\mathrm{N} / \mathrm{A}$ \\
\hline U1-Nrnp-Ab & $\mathrm{N}$ & $\mathrm{n}$ & $\mathrm{N}$ & $\mathrm{N} / \mathrm{A}$ \\
\hline Anti-SSA & $\mathrm{N}$ & $\mathrm{n}$ & $\mathrm{N}$ & $\mathrm{N} / \mathrm{A}$ \\
\hline Ro-52-Ab & $\mathrm{N}$ & $\mathrm{n}$ & $\mathrm{N}$ & $\mathrm{N} / \mathrm{A}$ \\
\hline Anti-SSB & $\mathrm{N}$ & $\mathrm{n}$ & $\mathrm{N}$ & $\mathrm{N} / \mathrm{A}$ \\
\hline Scl-70-Ab & $\mathrm{N}$ & $\mathrm{n}$ & $\mathrm{N}$ & N/A \\
\hline Jo-1-Ab & $\mathrm{N}$ & $\mathrm{n}$ & $\mathrm{N}$ & $\mathrm{N} / \mathrm{A}$ \\
\hline dsDNA-Ab & $\mathrm{N}$ & $\mathrm{n}$ & $\mathrm{N}$ & $\mathrm{N} / \mathrm{A}$ \\
\hline AnuA-Ab & $\mathrm{N}$ & $\mathrm{n}$ & $\mathrm{N}$ & $\mathrm{N} / \mathrm{A}$ \\
\hline PCNA-Ab & $\mathrm{N}$ & $\mathrm{n}$ & $\mathrm{N}$ & N/A \\
\hline AMA-M2 & $\mathrm{N}$ & $\mathrm{n}$ & $\mathrm{N}$ & $\mathrm{N} / \mathrm{A}$ \\
\hline AHA-Ab & $\mathrm{N}$ & $\mathrm{n}$ & $\mathrm{N}$ & N/A \\
\hline PM-Scl-Ab & $\mathrm{N}$ & $\mathrm{n}$ & $\mathrm{N}$ & N/A \\
\hline r-Prot-Ab & $\mathrm{N}$ & $\mathrm{n}$ & $\mathrm{N}$ & $\mathrm{N} / \mathrm{A}$ \\
\hline AKA & $\mathrm{N}$ & $\mathrm{n}$ & $\mathrm{N}$ & $\mathrm{N} / \mathrm{A}$ \\
\hline anti-PLT & $\mathrm{N}$ & $\mathrm{n}$ & $\mathrm{N}$ & $\mathrm{N} / \mathrm{A}$ \\
\hline
\end{tabular}

ESR, erythrocyte sedimentation rate; Ig, immunoglobulin; $\mathrm{C}$, complement; ASO, anti-streptolysin O; RF, rheumatoid factors; ACA, anti-cardiolipin; ANCA, anti-neutrophil; ANA, antinuclear; Sm, anti-Smith; U1-Nrnp, anti-U1-nuclear ribonucleoprotein; Ab, antibody; Anti-SSA, anti-Ro/Sjögren's-syndrome-related antigen A; Anti-SSB, anti-La/Sjögren's-syndrome-related antigen B; AnuA, anti-nucleosome; PCNA, anti-proliferating cell nuclear antigen; AMA-M2, anti-mitochondrial-M2; AHA, anti-histone; r-Prot, anti-ribosomal P-protein; AKA, anti-keratin; anti-PLT, anti-platelet; $\mathrm{N}$, negative; $\mathrm{n}$, normal; +, positive change; -, negative change.

anti-La/Sjögren's-syndrome-related antigen B, anti-Scl-70, anti-Jo-1, anti-dsDNA, anti-nucleosome, anti-proliferating cell nuclear antigen, anti-mitochondrial-M2, anti-histone, anti-PM-Scl, anti-ribosomal P-protein, anti-keratin and anti-neutrophil cytoplasmic antibodies were normal (Table II), determined using immunoturbidimetry, in accordance with a previous study (12). IgG levels were detected by immunoturbidimetry with an IMMAGE 800 system (Beckman Coulter, Inc., Brea, CA, USA). A bone marrow smear examination detected no obvious abnormalities. Additional assays were conducted as follows: ACA and anti-neutrophil antibodies were detected using western blotting (data not shown); anti-hepatitis $\mathrm{C}$ and anti human immunodeficiency virus using an enzyme-linked immunosorbent assay (ELISA; 

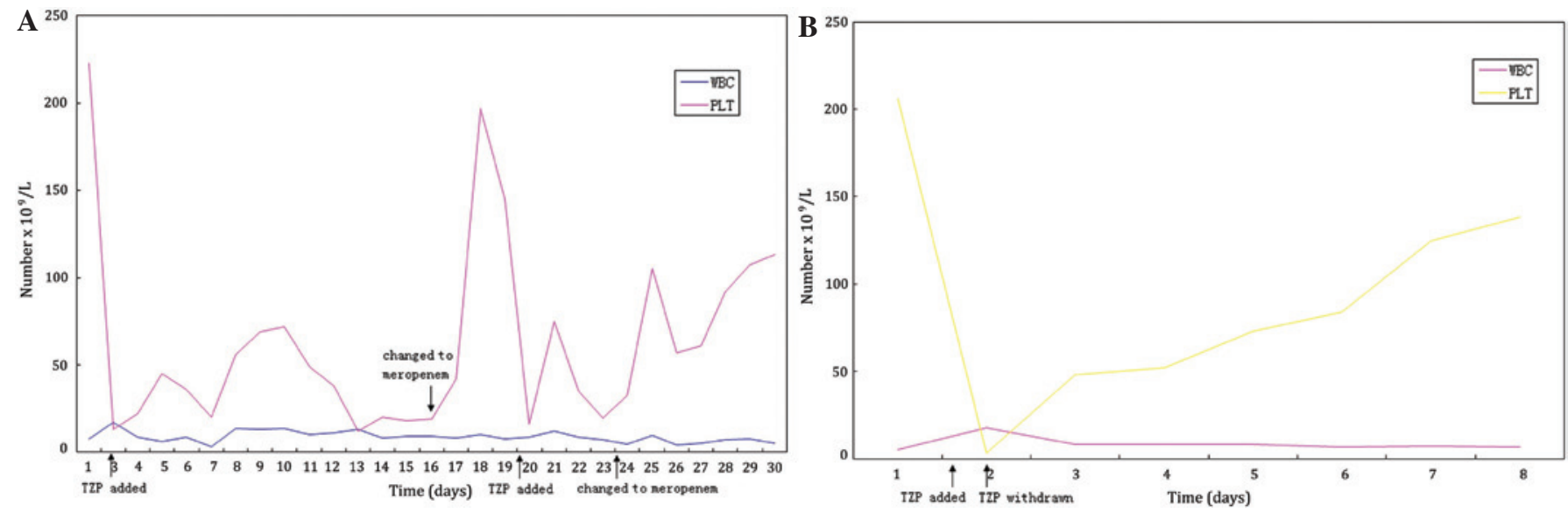

Figure 1. Alterations in the levels of WBC and PLT following TZP treatment at (A) first and (B) the second admission. Arrows indicate times of the indicated treatments. WBC, white blood cells; PLT, platelets; TZP, tazobactam and piperacillin.

Table III. WBC and PLT levels altered over time following the second TZP treatment.

\begin{tabular}{lrr}
\hline Day & WBC $\left(\times 10^{9} / 1\right)$ & PLT $\left(\times 10^{9} / 1\right)$ \\
\hline 1 & 5.4 & 206 \\
4 & 17.6 & 3 \\
5 & 8.2 & 48 \\
6 & 8 & 52 \\
7 & 8 & 73 \\
8 & 6.7 & 84 \\
9 & 7.1 & 125 \\
10 & 6.5 & 138 \\
\hline
\end{tabular}

TZP treatment was initiated and withdrawn on day 4 following admission of the patient. WBC, white blood cells; PLT, platelets; $\mathrm{TZP}$, tazobactam and piperacillin.

Zhuhai Livzon Diagnostics, Inc., Zhuhai, China); and platelet antibodies using a solid-phase antiglobulin test using an immunity micro column incubator (Changchun Boyan Technology Instrument Co., Ltd., Changchun, China). Assays for ACA, anti-neutrophil, anti-hepatitis $\mathrm{C}$ virus, anti-human immunodeficiency virus and plasma platelet antibodies were negative (13). Furthermore, the thyroid function of the patient was normal, and the liver and spleen sizes were demonstrated to be normal via an abdominal B ultrasound. The patient was discharged from the hospital after 41 days of treatment.

In December 2013, the same patient was re-hospitalized complaining of an inability to swallow, pulmonary aspiration and a high temperature. The patient was diagnosed with aspiration pneumonia and was treated with $4.5 \mathrm{~g}$ TZP every $8 \mathrm{~h}$, in order to eliminate the infection; however, on the same day, the levels of platelets were markedly reduced to $3 \times 10^{9}$ platelets/1, as determined via manual counting. Conversely, substitution of TZP treatment with cefoperazone (dose, $2.0 \mathrm{~g}$; administered every $8 \mathrm{~h}$ intravenously) resulted in the platelet levels returning to normal after 5 days, suggesting that there was an association between TZP and the occurrence of thrombocytopenia. Therefore, the initial diagnosis of idiopathic thrombocytopenic purpura was revised to drug-induced thrombocytopenia (Table III and Fig. 1B).

\section{Discussion}

TZP treatment is commonly used in the ICU; however, TZP-induced thrombocytopenia is not commonly reported. In the present study, an elderly patient admitted to the ICU presented with thrombocytopenia, which was associated with TZP treatment. Clinical laboratory results demonstrated that the TZP-induced thrombocytopenia was abrupt $(12 \mathrm{~h}$ later it had markedly decreased) and reversible, as platelet numbers were normal within 3-5 days following withdrawal of TZP. Although the platelet count decreased following treatment with methylprednisolone and gamma globulin, the platelet number remained particularly low for 1 month. However, subsequent to withdrawal of TZP treatment, the platelet level increased, confirming the hypothesis that thrombocytopenia was induced by TZP.

The main reason that doctors may ignore the association between TZP treatment and platelet reduction is that it has only rarely been reported in the literature $(10,14,15)$. The present study suggested that doctors should be aware of the risks of TZP-induced thrombocytopenia, and that TZP treatment should be discontinued following detection of drug-induced thrombocytopenia.

The mechanism underlying TZP-induced thrombocytopenia is currently unclear. Previous studies have suggested that drug-induced thrombocytopenia may occur due to drug-induced suppression of the bone marrow $(16,17)$. Conversely, other studies have suggested that TZP, which is a 500-1,000 Da drug, may associate with the platelet membrane antigen, stimulating the body to produce antibodies against the TZP-platelet complex; this, in turn, may activate the complement system in order to promote platelet destruction (18-20). In the present study, the adverse effects of TZP were predominantly associated with immune-mediated thrombocytopenia; however, the molecular pathogenesis underlying TZP-induced thrombocytopenia has yet to be elucidated and requires additional study. 


\section{Acknowledgements}

The present study was supported by grants from the Ningbo Natural Science Foundation of China (grant no. 2013A610234), the Zhejiang Natural Science Foundation of China (grant no. LQ15H150001) and the Chinese Medicine Research Program of Zhejiang Province, China (grant no. 2015ZA185). The authors of the present study would like to thank Dr Xiang Hou (Ningbo University, Ningbo, China) for assistance in platelet quantification.

\section{References}

1. Bautista AP, Buckler PW, Towler HM, Dawson AA and Bennett B: Measurement of platelet life-span in normal subjects and patients with myeloproliferative disease with indium oxine labeled platelets. Br J Haematol 58: 679-687, 1985.

2. Smock KJ and Perkins SL: Thrombocytopenia: An update. Int J Lab Hematol 36: 269-278, 2014.

3. Provan D, Stasi R, Newland AC, Blanchette VS, Bolton-Maggs P, Bussel JB, Chong BH, Cines DB, Gernsheimer TB, Godeau B, et al: International consensus report on the investigation and management of primary immune thrombocytopenia. Blood 115: 168-186, 2010.

4. Gonçalves-Pereira J and Póvoa P: Antibiotics in critically ill patients: A systematic review of the pharmacokinetics of $\beta$-lactams. Crit Care 15: R206, 2011.

5. Bourget P, Lesne-Hulin A, Le Reveillé R, Le Bever H and Carsin H: Clinical pharmacokinetics of piperacillin-tazobactam combination in patients with major burns and signs of infection. Antimicrob Agents Chemother 40: 139-145, 1996.

6. Finsterer $\mathrm{J}$ and Kotzailias N: Thrombocytosis under ciprofloxacin and tazobactam/piperacillin. Platelets 14: 329-331, 2003.

7. Reichardt P, Handrick W, Linke A, Schille R and Kiess W: Leukocytopenia, thrombocytopenia and fever related to piperacillin/tazobactam treatment - a retrospective analysis in 38 children with cystic fibrosis. Infection 27: 355-356, 1999.
8. Anand A and Chauhan HK: Piperacillin and vancomycin induced severe thrombocytopenia in a hospitalized patient. Platelets 22: 294-301, 2011

9. Macwilliam JL, Mistry R, Floyd MS Jr and Baird AD: Piperacillin/tazobactam induced thrombocytopaenia - a delayed response. BMJ Case Rep 2012: bcr0320125981, 2012.

10. Uzun G, Onem Y, Hatipoglu M, Turhan V, Mutluoglu M and Ay H: Piperacillin/tazobactam-induced neutropenia, thrombocytopenia, and fever during treatment of a diabetic foot infection. Scand J Infect Dis 45: 73-76, 2013.

11. Ramot Y and Nyska A: Drug-Induced Thrombosis - Experimental, clinical, and mechanistic considerations. Toxicol Pathol 35: 208-225, 2007.

12. Cines DB, Bussel JB, Liebman HA and Luning Prak ET: The ITP syndrome: Pathogenic and clinical diversity. Blood 113: 6511-6521, 2009.

13. Zhang L, Li H, Zhao H, Ji L and Yang R: Hepatitis C virus-related adult chronic idiopathic thrombocytopenic purpura: Experience from a single Chinese centre. Eur J Haematol 70: 196-197, 2003.

14. Macwilliam JL, Mistry R, Floyd MS Jr and Baird AD: Piperacillin/tazobactam-induced thrombocytopenia - a delayed response. BMJ Case Rep, 2012.

15. Shaik S, Kazi HA and Ender PT. Rapid-onset piperacillin-tazobactam induced thrombocytopenia. J Pharm Pract 28: 204-206, 2015.

16. Ruiz-Irastorza G, Barreiro G and Aguirre C: Reversible bone marrow depression by high-dose piperacillin/tazobactam. Br J Haematol 95: 611-612, 1996.

17. Kumar A, Choudhuri G and Aggarwal R: Piperacillin induced bone marrow suppression: A case report. BMC Clin Pharmacol 3 . 2, 2003.

18. Kelton JG, Meltzer D, Moore J, Giles AR, Wilson WE, Barr R, Hirsh J, Neame PB, Powers PJ, Walker I, et al: Drug-induced thrombocytopenia is associated with increased binding of $\mathrm{IgG}$ to platelets both in vivo and in vitro. Blood 58: 524-529, 1981.

19. Pérez-Vázquez A, Pastor JM and Riancho JA: Immune thrombocytopenia caused by piperacillin/tazobactam. Clin Infect Dis 27: 650-651, 1998

20. Grégoire C, Brumpt C, Loirat D, Lau N, Bruel C, Philippart F, Couzigou C, Garrouste-Orgeas M and Misset B: A case of daptomycin-induced immune thrombocytopenia. Antimicrob Agents Chemother 56: 6430-6431, 2012. 